\title{
Effects of Antihypertensive Agents on Intestinal Contractility in the Spontaneously Hypertensive Rat: Angiotensin Receptor System Downregulation by Losartan
}

\author{
Glen Stephen Patten and Mahinda Yapa Abeywardena \\ CSIRO Health and Biosecurity, Adelaide BC, South Australia, Australia \\ Received September 6, 2016; accepted November 21, 2016
}

\begin{abstract}
Hypertension is an inflammatory condition controlled by the renin angiotensin system and is linked to kidney disease, diabetes mellitus, and recently to dysfunction of the gut. The aim of this study was to determine what effect antihypertensive drug treatments may have on intestinal function of the spontaneously hypertensive rat (SHR). In the first experiment, SHRs were treated with enalapril, hydralazine, or with no treatment as a control. In the second experiment, SHRs were treated with losartan or with no treatment as a control. All drug treatments led to significant lowering of blood pressure after 16 weeks. At termination, intact tissue sections of the ileum and colon were induced to contract ex vivo by $\mathrm{KCl}$; electrical stimulation; and agonists carbachol, angiotensin II, and prostaglandin $\mathrm{E}_{2}\left(\mathrm{PGE}_{2}\right)$. There were no differences in ileal or colonic contractility due to
\end{abstract}

\section{Introduction}

The major bioactive component of the renin-angiotensin system (RAS) is the potent vasoconstrictor angiotensin II (Ang II), which is formed from angiotensin I (Ang I) by angiotensin-converting enzyme (ACE), which is located in lung, kidney, and gut tissue (Duggan et al., 1989). Although the main pathophysiological impact of RAS has been centered on cardiovascular and renal biology, dense populations of angiotensin receptor subtypes have been reported in the mucosa and muscularis layers of human and rat ileum and colon in both human and animal studies alike (Hirasawa et al., 2002; Spak et al., 2008). Further, a human homolog of ACE, angiotensin-converting enzyme 2 (ACE2), constitutes a new enzymatic pathway that generates Ang 1-7 from Ang II and binds to the putative MAS receptor, leading to vasodilation and cardiovascular protection, thus opposing the effects of Ang II (Donoghue et al., 2000; Tipnis et al., 2000; Kuba et al., 2013). In addition, it has been recently revealed that, via its function in amino acid transport, ACE2 controls intestinal inflammation and diarrhea and plays a role in regulating the microbiome (Hashimoto et al., 2012; Perlot and Penninger, 2013). These findings strongly link RAS to regulation and health of the gastrointestinal system (Cole-Jeffrey et al., 2015).

This work was fully funded by CSIRO Health and Biosecurity, Kintore Avenue, Adelaide, South Australia.

dx.doi.org/10.1124/jpet.116.237586. hydralazine or enalapril compared with no-treatment SHR control. However, for the ileum, the losartan group responded significantly more to $\mathrm{KCl}$ and carbachol while responding less to angiotensin II, with no difference for $\mathrm{PGE}_{2}$ compared with the no-treatment SHR control. In contrast, the colon responded similarly to $\mathrm{KCl}$, electrical stimulation, and $\mathrm{PGE}_{2}$ but responded significantly less to angiotensin II. These results demonstrate that the ileum responds differently (with $\mathrm{KCl}$ and carbachol as agonists) to the colon after losartan treatment, whereas there is a reduced contractile response in both the ileum and colon following losartan treatment. Although there are few well documented major contraindications for angiotensin receptor blockers, the modulation of gut contractility by losartan may have wider implications for bowel health.

ABBREVIATIONS: ACE, angiotensin-converting enzyme; Ang, angiotensin; ARB, angiotensin receptor blocker; $\mathrm{AT}_{1}$, angiotensin type 1; BP, blood pressure; $\mathrm{PGE}_{2}$, prostaglandin $\mathrm{E}_{2}$; RAS, renin-angiotensin system; SHR, spontaneously hypertensive rat. 
for muscarinic or peptide-stimulated contraction of gut tissue (Patten et al., 2004, 2005). It is known that hypotension induced by the ACE inhibitor captopril involves a prostaglandindependent component (Pontieri et al., 1990). However, it is unknown to what extent the RAS interacts with prostanoid generation and how antihypertensive agents may influence contractility and motility of the gut.

The aim of this study was to examine the effects of long-term treatment with three classes of antihypertensive agents as: an ACE inhibitor, enalapril; an ARB, losartan; and the arterial relaxant hydralazine as a positive control on SHR gut contractility. Separate no-treatment SHRs were used as controls. To do this, we examined the effects of these antihypertensive agents on the ex vivo induced contractility of intact sections of ileum and colon by $\mathrm{KCl}$; electrical stimulation; and muscarinic, prostanoid, and angiotensin receptor-dependent agonists (Patten et al., 2004, 2005, 2015a,b). We hypothesize that antihypertensive drugs may affect intestinal contractility and motility.

\section{Materials and Methods}

Animal Experiments. Forty 12 -week-old SHRs were delivered to the CSIRO small-animal facility from the Animal Resource Centre breeding facility in Western Australia (24 animals for experiment 1 and 16 animals for experiment 2 ). The animals were allowed 2 weeks to acclimatize in a 12-hour light/dark cycle at $22^{\circ} \mathrm{C}$, and were ear-tagged and weighed. Animals were caged in groups of no more than five animals in the standard colony wire cages to decrease coprophagy and prevent the ingestion of bedding materials. Environmental enrichment was provided to allow animals to rest away from the wirebased floor. Animals were fed an AIN93M diet (ICN Biomedicals, Irvine, CA) (13.6\% protein, $4.0 \%$, fat, $4.7 \%$ crude fiber, and $15.1 \mathrm{MJ} / \mathrm{kg}$ digestible energy) ad libitum and were monitored daily and weighed weekly. For experiment 1, at 14 weeks of age, three groups of eight animals were randomly assigned on a weight basis to be administered the antihypertensive agents hydralazine $(0.012 \%$, w/v) or enalapril maleate ( $4 \mathrm{mg} / \mathrm{kg}$ per day) in the drinking water given ad libitum for 16 weeks or were assigned as no-treatment SHRs acting as the control group. For experiment 2, at 14 weeks, two other groups of eight animals were randomly assigned on a weight basis to be administered the antihypertensive losartan (10 mg/kg per day) in the drinking water given ad libitum for 16 weeks or were assigned as no-treatment SHRs as control. Sixteen weeks of treatment was undertaken to allow the animals to reach full maturity and stable blood pressure in the no-treatment SHR control groups. All drugs and fine chemicals were from Sigma Australia Pty. Ltd. (Sydney, Australia). All experimental protocols were undertaken in accordance with the Australian code for the care and use of animals for scientific purposes (8th edition, 2013, https://www.nhmrc.gov.au/guidelines-publications/ea28) and approved by the CSIRO Animal Ethics Committee and included power calculations.

Blood Pressure Measurements. For experiments 1 and 2, systolic blood pressure was measured in conscious rats from 14 weeks, every 2 weeks for the 16 -week treatment phase. Blood pressure (BP) was measured using an indirect tail-cuff method at $30^{\circ} \mathrm{C}$ in measuring tubes using an electro-sphygmomanometer combined with a pneumatic pulse transducer/amplifier (model 6m22931, six-channel NIBP system, Mediquip Pty Ltd, Loganholme, Qld, Australia) using BpMonWin Monitor version 1.33 software (IITC Life Science, Woodland Hills, CA). Rats were acclimatized in the measuring tubes twice before BP measurements were commenced.

Measurement of Ileal and Colonic Tissue Contractility Ex Vivo. Methodology for inducing contractility and magnitude measurements for both the ileum and colon have been described in detail previously (Patten et al., 2002, 2015; Bajka et al., 2010). Animals were euthanized via exsanguination while still under anesthesia $(60 \mathrm{mg} / \mathrm{kg}$
Nembutal, sodium pentobarbitone, Sigma Chem Co, Sydney, Australia). Death of the animal was confirmed by the removal of the heart. In brief, sections of both the terminal ileum $(4-5 \mathrm{~cm})$ between 2 and $10 \mathrm{~cm}$ from the ileo-caecal junction and proximal colon (3-4 cm) were excised $2 \mathrm{~cm}$ from the caecal-colonic junction. Both the colon and ileum were mounted in tandem in organ chambers with a modified Krebs-Henseleit bicarbonate buffer, and the colon was excited by an electric field to induce contraction (Bajka et al., 2010). The gastrointestinally active compounds were then added sequentially to both ileal and colonic baths as follows: $\mathrm{KCl}(5-35 \mathrm{mM})$, carbachol $(0.03-22 \mu \mathrm{M})$, angiotensin II $(0.001-10 \mu \mathrm{M})$, and $\mathrm{PGE}_{2}(0.001-10 \mu \mathrm{M})$. Dose-response curves were generated by cumulative additions of a small bolus of $\mathrm{KCl}$ or agonist to the incubated tissue in the organ bath until contraction reached a plateau (normally after 3-5 minutes). The solution in the organ bath was washed out when maximal contraction was reached, ready for subsequent testing of contractility. No refractoriness was recorded after KCl, carbachol, angiotensin II, or $\mathrm{PGE}_{2}$ treatments. To assess this, $1 \mu \mathrm{M}$ carbachol was added at the completion of the experiment, and only tissues with $100 \%$ recovery of contractile activity were used for experimental determinations.

Statistical Analysis. Data were summarized as the mean \pm S.E.M. Comparisons between two groups were conducted using the unpaired Student's $t$ test, whereas comparison of groups of three was performed using one-way analysis of variance followed by the Bonferroni multiple comparison test using GraphPad Instat 3.0 (GraphPad Software, La Jolla, CA). Statistical significance was set at $P<0.05$.

\section{Results}

Blood Pressure. For experiment 1, the initial and final BP for no-treatment SHR control, enalapril, and hydralazine SHR were $212.4 \pm 3.7$ and $221.5 \pm 1.0,212.3 \pm 4.6$ and $171.1 \pm 1.8$, and $203.2 \pm 2.2$ and $138.2 \pm 2.5$, respectively. For experiment 2 , the initial and final BP for no-treatment SHR control and losartan SHR were $210 \pm 3.6$ and $220.9 \pm 2.2$, and $215 \pm 3.3$ and $186.4 \pm 3.4$, respectively. All drug treatments led to significantly lower blood pressure in the SHR $(P<0.05)$ compared with the no-treatment SHR control group. At the doses used, the hydralazine treatment group had a lower final blood pressure than the enalapril and losartan treatment groups $(P<0.05)$.

Contractility of Ileum and Colon Ex Vivo, Experiment 1. In the ileum, there were no differences in contraction due to $\mathrm{KCl}$ for the enalapril and hydralazine groups compared with no-treatment SHR controls (Table 1). For the colon, there were no differences in contraction due to $\mathrm{KCl}$ or electrical stimulation for the enalapril- and hydralazine-treated groups compared with no-treatment SHR controls (Table 2). For both the ileum (Fig. 1) and colon (Fig. 2), there were no differences in maximal contractility $(\mathrm{mm} / \mathrm{g})$ or sensitivity $\left(\mathrm{EC}_{50}\right)$ in response to concentration dose curves of carbachol, angiotensin II, and $\mathrm{PGE}_{2}$. There was a depressed response to $\mathrm{PGE}_{2}$ in the ileum and colon compared with what we have found previously for control Wistar Kyoto rats (results not shown) (Patten et al., 2004, 2005).

Contractility of Ileum and Colon Ex Vivo, Experiment 2. For the ileum, the contractility responses to 10 and $40 \mathrm{mM}$ $\mathrm{KCl}$ were higher for the losartan-treated group compared with the no-treatment SHR control group (Table 3). For the colon, however, there were no differences in response to $\mathrm{KCl}$ or electrical stimulation between the no-treatment SHR control or losartan groups (Table 3). For the ileum, with respect to losartan treatment, there was a higher contractile response to carbachol (Fig. 3A; Table 3) and lower responses to angiotensin II (Fig. 3B; Table 3), which also demonstrated 


\section{TABLE 1}

Experiment 1, effects of antihypertensive agents enalapril and hydralazine in drinking water for 16 weeks on the contractility of SHR isolated intact sections of ileum ex vivo by $\mathrm{KCl}$ and agonists carbachol, angiotensin II, and $\mathrm{PGE}_{2}$ compared with no-treatment SHR control

Results are the mean \pm S.E.M. from six to eight rats. Statistics were performed using one-way analysis of variance. There were no significant differences between the groups (results not shown).

\begin{tabular}{|c|c|c|c|}
\hline & Control & Enalapril & Hydralazine \\
\hline \multicolumn{4}{|l|}{$\mathrm{KCl}(40 \mathrm{mM})$} \\
\hline $\operatorname{Max}(\mathrm{mm} / \mathrm{g})$ & $71.2 \pm 15.8$ & $74.3 \pm 12.4$ & $63.0 \pm 9.5$ \\
\hline \multicolumn{4}{|l|}{ Carbachol } \\
\hline $\mathrm{EC}_{50}(\mathrm{nM})$ & $137 \pm 26$ & $300 \pm 70$ & $255 \pm 24$ \\
\hline $\operatorname{Max}(\mathrm{mm} / \mathrm{g})$ & $92.4 \pm 8.7$ & $98.9 \pm 13.2$ & $83.1 \pm 9.6$ \\
\hline AUC & $141 \pm 18$ & $169 \pm 23$ & $137 \pm 20$ \\
\hline \multicolumn{4}{|l|}{ Angiotensin II } \\
\hline $\mathrm{EC}_{50}(\mathrm{nM})$ & $12.0 \pm 1.5$ & $17.2 \pm 3.7$ & $23.2 \pm 5.8$ \\
\hline $\operatorname{Max}(\mathrm{mm} / \mathrm{g})$ & $52.9 \pm 6.6$ & $46.3 \pm 7.6$ & $51.0 \pm 7.4$ \\
\hline AUC & $82.1 \pm 9.9$ & $72.2 \pm 14.9$ & $74.3 \pm 13.6$ \\
\hline \multicolumn{4}{|l|}{$\mathrm{PGE}_{2}$} \\
\hline $\mathrm{EC}_{50}(\mathrm{nM})$ & $1624 \pm 249$ & $3813 \pm 1002$ & $2169 \pm 562$ \\
\hline $\operatorname{Max}(\mathrm{mm} / \mathrm{g})$ & $39.0 \pm 8.2$ & $40.0 \pm 6.6$ & $47.5 \pm 6.7$ \\
\hline AUC & $29.0 \pm 5.4$ & $35.2 \pm 12.1$ & $43.7 \pm 9.0$ \\
\hline
\end{tabular}

AUC, area under the curve as arbitrary units; Max, maximal derived contraction of the tissue.

lower sensitivity (higher $\mathrm{EC}_{50}$ ) (Fig. 3B; Table 3), with no difference noted for $\mathrm{PGE}_{2}$ (Fig. 3C; Table 3) compared with the no-treatment SHR control group. For the colon, with respect to losartan treatment, there were no differences in contractile responses to carbachol (Fig. 4A; Table 3) or $\mathrm{PGE}_{2}$ (Fig. 4C; Table 3), with lower responses noted for angiotensin II (Fig. 4B; Table 3) with concomitant lower sensitivities (higher $\mathrm{EC}_{50}$ ) (Table 3) compared with the no-treatment SHR control group. For experiment 2, there were no differences noted in the mean tissue densities of ilea or colons from the losartan-treated group compared with the no-treatment SHR control group (Table 3).

\section{Discussion}

The RAS is involved in the development of essential hypertension, which is an inflammatory condition that not only influences the cardiovascular system but dysregulates glucose control and kidney disease and can also influence gut microbiota and the functionality of the gut (Kuba et al., 2013; Yang et al., 2015; Zhu et al., 2016). We examined the effects that three classes of antihypertensive drugs may have on SHR gut function after 16 weeks of treatment. In the first experiment, SHRs were treated with the ACE inhibitor enalapril and the direct-acting smooth muscle arteriole relaxant hydralazine, which resulted in no significant differences in gut contractility in response to all agents tested ex vivo compared with no-treatment SHR controls. In human patients undergoing hypertension treatment, complications to the gut due to ACE inhibitors are uncommon. However, they have been reported to induce intestinal angioedema that may lead to unnecessary invasive procedures, such as exploratory laparotomy (Weingärtner et al., 2009), but to our knowledge, contraindications for gut motility have not been reported. Indeed, in animal models such as the mouse, enalaprilat has been shown to reduce the severity of dextran sulfate sodium-induced colitis and reduce tumour necrosis factor- $\alpha$ levels and epithelial cell apoptosis (Spencer et al., 2007), whereas enalapril was shown to
TABLE 2

Experiment 1, effects of antihypertensive agents enalapril and hydralazine in the drinking water for 16 weeks on the contractility of SHR isolated intact sections of proximal colon ex vivo by $\mathrm{KCl}$; electrical stimulation; and agonists carbachol, angiotensin II, and $\mathrm{PGE}_{2}$ compared with no-treatment SHR control

Results are mean \pm S.E.M. from six to eight rats. Statistics were performed using one-way analysis of variance. There were no significant differences between the groups (results not shown).

\begin{tabular}{|c|c|c|c|}
\hline & Control & Enalapril & Hydralazine \\
\hline \multicolumn{4}{|l|}{$\mathrm{KCl}(40 \mathrm{mM})$} \\
\hline $\operatorname{Max}(\mathrm{mm} / \mathrm{g})$ & $21.2 \pm 3.7$ & $19.7 \pm 3.6$ & $20.1 \pm 4.5$ \\
\hline \multicolumn{4}{|c|}{ Electrical stimulation } \\
\hline $\operatorname{Max}(\mathrm{mm} / \mathrm{g})$ & $17.1 \pm 1.7$ & $14.5 \pm 3.4$ & $13.5 \pm 2.4$ \\
\hline \multicolumn{4}{|l|}{ Carbachol } \\
\hline $\mathrm{EC}_{50}(\mathrm{nM})$ & $159 \pm 27$ & $186 \pm 57$ & $207 \pm 77$ \\
\hline $\operatorname{Max}(\mathrm{mm} / \mathrm{g})$ & $40.7 \pm 6.6$ & $32.9 \pm 5.2$ & $41.7 \pm 4.4$ \\
\hline AUC & $79.7 \pm 12.8$ & $63.5 \pm 7.5$ & $79.6 \pm 11.4$ \\
\hline \multicolumn{4}{|l|}{ Angiotensin II } \\
\hline $\mathrm{EC}_{50}(\mathrm{nM})$ & $2.7 \pm 0.5$ & $2.7 \pm 0.7$ & $3.3 \pm 0.7$ \\
\hline $\operatorname{Max}(\mathrm{mm} / \mathrm{g})$ & $32.7 \pm 3.4$ & $30.6 \pm 4.1$ & $32.4 \pm 3.0$ \\
\hline AUC & $72.7 \pm 8.7$ & $68.2 \pm 8.8$ & $68.9 \pm 7.0$ \\
\hline \multicolumn{4}{|l|}{$\mathrm{PGE}_{2}$} \\
\hline $\mathrm{EC}_{50}(\mathrm{nM})$ & $67.3 \pm 20.9$ & $52.7 \pm 17.8$ & $208 \pm 67$ \\
\hline $\operatorname{Max}(\mathrm{mm} / \mathrm{g})$ & $32.2 \pm 1.1$ & $32.3 \pm 2.4$ & $32.2 \pm 2.8$ \\
\hline AUC & $74.7 \pm 6.5$ & $79.1 \pm 7.5$ & $79.6 \pm 11.4$ \\
\hline
\end{tabular}

AUC, area under the curve as arbitrary units; Max, maximal derived contraction of the tissue.

attenuate the upregulation of $\mathrm{I} \kappa \mathrm{B} \alpha$ phosphorylation and reduced the severity of colitis as assessed by histologic examination (Lee et al., 2014).

In this study, we used hydralazine, a non-nucleoside DNA methyltransferase inhibitor and a potent arterial vasodilator (Knowles et al., 2004), which is approved for the treatment of severe hypertension and heart failure (Graça et al., 2014). Hydralazine is not routinely used as a primary drug for treating human hypertension because it elicits a reflex sympathetic stimulation of the heart (the baroreceptor reflex). The sympathetic stimulation may increase heart rate and cardiac output and, in patients with coronary artery disease, may cause angina pectoris or myocardial infarction. However, in animal models, this class of drug can inhibit gastric emptying in rats and inhibit gastrointestinal propulsion in mice (Chiba et al., 1981), but this dysmotility was not evident for ex vivo intestinal contractility in hydralazine-treated SHRs used in this study.

Losartan is an orally active, nonpeptide $\mathrm{AT}_{1}$ receptor antagonist which provides a more specific and complete blockade of the actions of angiotensin II than renin or ACE inhibitors (Simpson and McClellan, 2000) and is effective in controlling BP and longterm renal damage in hypertensive patients. Although it has been reported that a specific $\mathrm{ARB}$, olmesartan, may interfere with gut immune homeostasis, is known to cause rare cases of sprue-like enteropathy in predisposed individuals, and is associated with an increased risk of hospitalization for intestinal malabsorption and celiac disease (Sciolom et al., 2015; Basson et al., 2016), losartan has been reported to be well tolerated alone and in combination, with only limited reports of gastrointestinal side effects, such as constipation (Weber, 1997; Gokhale et al., 2002), and generally no association with increased risk of cancer for ARBs (Bhaskaran et al., 2012).

In our study with SHRs, losartan treatment led to increased receptor-independent $\mathrm{KCl}$-induced depolarization-driven ileal contractility that was not evident for the colon. There was also an increased ileal contractility after losartan treatment with the muscarinic-mimetic carbachol with no significant change 

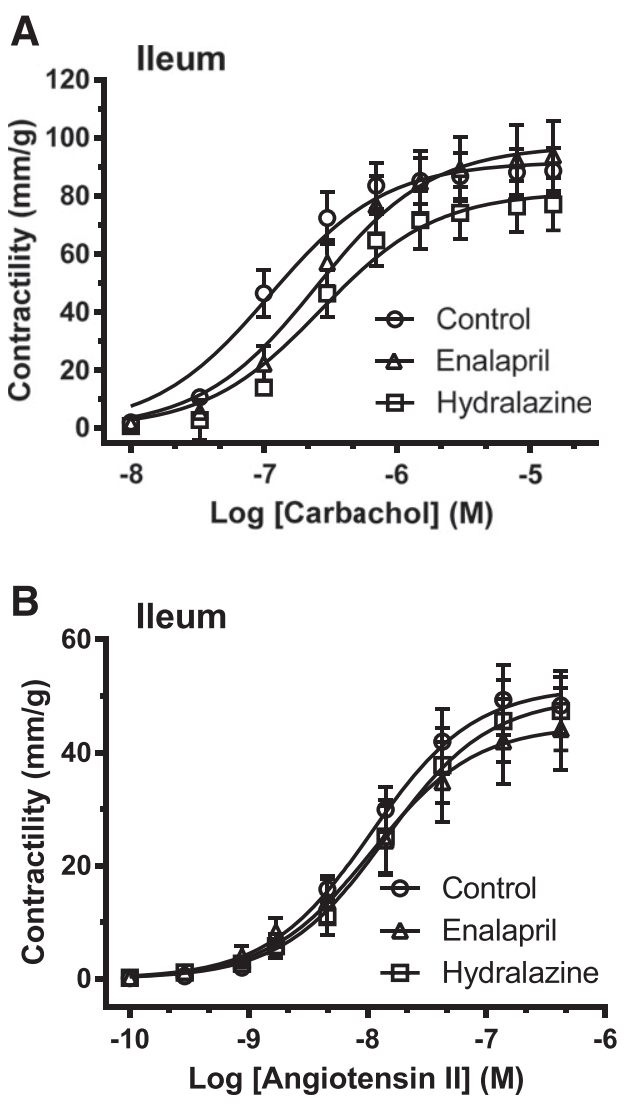

C

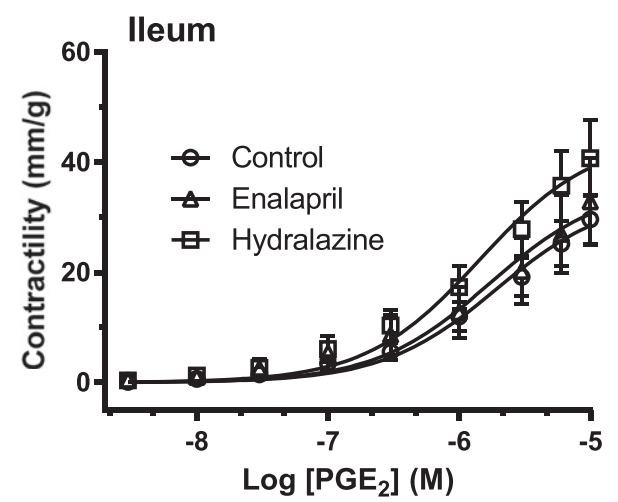

Fig. 1. Experiment 1. The dose accumulative effects of carbachol (A), angiotensin II (B), and $\mathrm{PGE}_{2}$ (C) on intact ileal sections ex vivo after 16 -week treatment with enalapril (triangles) or hydralazine (squares) from 25-week-old SHRs compared with no-treatment SHR controls (circles). The data are expressed as the mean \pm S.E.M. from six to eight rats. Using analysis of variance, there were no significant differences in maximal contractions or sensitivities in response to the gastrointestinal active agents across the groups. The calculated maximal contraction $(\mathrm{mm} / \mathrm{g})$, sensitivity $\left(\mathrm{EC}_{50}\right)$, and area under the curve for each gastrointestinally active agent in the ileum are shown in Table 1.

in sensitivity $\left(\mathrm{EC}_{50}\right)$ and no effects noted for the colon. Electricalstimulated colon also demonstrated no difference in the response to losartan treatment. Although the prostanoid response is depressed in SHRs (Patten et al., 2004, 2005), there was also no change in ileal or colonic response to the prostanoid $\mathrm{PGE}_{2}$. However, losartan treatment led to a large suppression of both ileal and colonic response to angiotensin II. For the ileum, there was a concomitant decrease in sensitivity to angiotensin II. The colon showed decreased sensitivity to angiotensin II. The
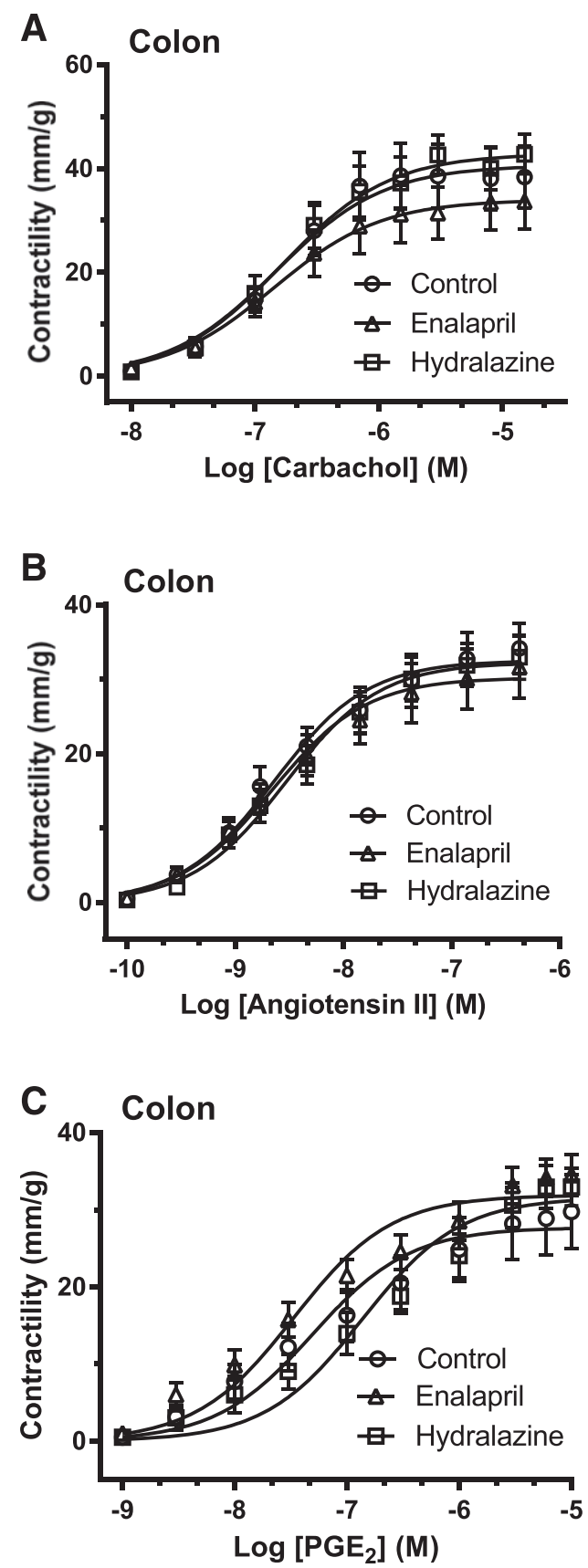

Fig. 2. Experiment 1. The dose accumulative effects of carbachol (A), angiotensin II (B), and $\mathrm{PGE}_{2}$ (C) on intact colonic sections ex vivo after 16-week treatment with enalapril (triangles) or hydralazine (squares) from 25-week-old SHRs compared with no-treatment SHR controls (circles). The data are expressed as the mean \pm S.E.M. from six to eight rats. Using analysis of variance, there were no significant differences in maximal contractions or sensitivities across the groups. The calculated maximal contraction $(\mathrm{mm} / \mathrm{g})$, sensitivity $\left(\mathrm{EC}_{50}\right)$, and area under the curve for each electrical stimulation and the gastrointestinally active agents in the colon are shown in Table 2.

changes in contractility due to losartan treatment could not be explained by changes in either ileal or colonic tissue density or muscle mass, which were not significantly different compared with no-treatment SHR controls. It is to be determined if other ARBs currently used in clinical settings have similar effects.

These differences in intestinal tissue responsiveness are difficult to explain, so the knowledge gap requires the investigation of the 


\section{TABLE 3}

Experiment 2, effects of losartan in drinking water for 16 weeks on SHR contractility of intact ileum and proximal colon sections ex vivo by $\mathrm{KCl}$, agonists (carbachol, angiotensin II, and $\mathrm{PGE}_{2}$ ), and electrically driven colon and tissue densities compared with no-treatment SHR control

Results are mean \pm S.E.M. from six to eight rats. Statistics were performed using Student's $t$ test.

\begin{tabular}{|c|c|c|c|}
\hline & Control & Losartan & $P$ Value \\
\hline \multicolumn{4}{|l|}{ Ileum } \\
\hline $\mathrm{KCl}(10 \mathrm{mM}) \operatorname{Max}(\mathrm{mm} / \mathrm{g})$ & $22.6 \pm 7.8$ & $61.1 \pm 10.1$ & 0.013 \\
\hline $\mathrm{KCl}(40 \mathrm{mM}) \mathrm{Max}(\mathrm{mm} / \mathrm{g})$ & $49.3 \pm 11.0$ & $108.3 \pm 12.2$ & 0.005 \\
\hline \multicolumn{4}{|l|}{ Carbachol } \\
\hline $\mathrm{EC}_{50}(\mathrm{nM})$ & $798 \pm 343$ & $253 \pm 23$ & $\mathrm{~ns}$ \\
\hline $\operatorname{Max}(\mathrm{mm} / \mathrm{g})$ & $79 \pm 17$ & $130 \pm 15$ & 0.048 \\
\hline AUC & $117 \pm 33$ & $226 \pm 29$ & 0.033 \\
\hline \multicolumn{4}{|l|}{ Angiotensin II } \\
\hline $\mathrm{EC}_{50}(\mathrm{nM})$ & $4.7 \pm 2.1$ & $43.1 \pm 13.2$ & 0.017 \\
\hline $\operatorname{Max}(\mathrm{mm} / \mathrm{g})$ & $82.5 \pm 18.1$ & $44.6 \pm 11.9$ & ns \\
\hline AUC & $194.7 \pm 55.6$ & $49.0 \pm 10.5$ & 0.028 \\
\hline \multicolumn{4}{|l|}{$\mathrm{PGE}_{2}$} \\
\hline $\mathrm{EC}_{50}(\mathrm{nM})$ & $2383 \pm 1081$ & $1463 \pm 266$ & $\mathrm{~ns}$ \\
\hline $\operatorname{Max}(\mathrm{mm} / \mathrm{g})$ & $48.4 \pm 12.3$ & $69.1 \pm 11.5$ & $\mathrm{~ns}$ \\
\hline AUC & $60.1 \pm 24.9$ & $68.6 \pm 11.5$ & $\mathrm{~ns}$ \\
\hline \multicolumn{4}{|l|}{ Colon } \\
\hline Electrical stimulation & $15.7 \pm 5.3$ & $14.0 \pm 3.0$ & $\mathrm{~ns}$ \\
\hline $\mathrm{KCl}(10 \mathrm{mM}) \mathrm{Max}(\mathrm{mm} / \mathrm{g})$ & $8.16 \pm 3.04$ & $4.11 \pm 1.16$ & $\mathrm{~ns}$ \\
\hline $\mathrm{KCl}(40 \mathrm{mM}) \mathrm{Max}(\mathrm{mm} / \mathrm{g})$ & $60.7 \pm 9.1$ & $57.7 \pm 8.1$ & $\mathrm{~ns}$ \\
\hline \multicolumn{4}{|l|}{ Carbachol } \\
\hline $\mathrm{EC}_{50}(\mathrm{nM})$ & $209 \pm 24$ & $170 \pm 8$ & $\mathrm{~ns}$ \\
\hline $\operatorname{Max}(\mathrm{mm} / \mathrm{g})$ & $74.4 \pm 9.0$ & $74.1 \pm 9.0$ & $\mathrm{~ns}$ \\
\hline AUC & $135 \pm 16$ & $140 \pm 18$ & $\mathrm{~ns}$ \\
\hline \multicolumn{4}{|l|}{ Angiotensin II } \\
\hline $\mathrm{EC}_{50}(\mathrm{nM})$ & $4.66 \pm 0.66$ & $241.0 \pm 91.1$ & 0.027 \\
\hline $\operatorname{Max}(\mathrm{mm} / \mathrm{g})$ & $27.1 \pm 6.7$ & $9.3 \pm 2.2$ & 0.030 \\
\hline AUC & $54.3 \pm 14.4$ & $4.5 \pm 0.9$ & 0.006 \\
\hline \multicolumn{4}{|l|}{$\mathrm{PGE}_{2}$} \\
\hline $\mathrm{EC}_{50}(\mathrm{nM})$ & $2078 \pm 941$ & $934 \pm 231$ & $\mathrm{~ns}$ \\
\hline $\operatorname{Max}(\mathrm{mm} / \mathrm{g})$ & $24.9 \pm 5.5$ & $16.1 \pm 2.0$ & $\mathrm{~ns}$ \\
\hline
\end{tabular}

AUC, area under the curve (as arbitrary units); Max, maximal derived contraction of the tissue; ns, not significant.

mechanisms for the losartan-induced changes in intestinal contractility. It is known that, in animal models of disease, transcription and translation of elements of the RAS may be regulated, and that $\mathrm{ARBs}$ such as losartan can modulate these effects (Sim and Chen, 2006). In a recent study, cardiac expressions of ACE and Mas were decreased in the hypertrophied left ventricle of SHRs, whereas those of the $\mathrm{AT}_{1}$ receptor and ACE2 were unchanged. Continuous perinatal losartan treatment reduced left ventricular weight but did not influence the altered cardiac RAS expression (Klimas et al., 2015). Since the ileal and colonic preparations undergo extensive washout prior to stimulation, it is very unlikely that residual losartan would explain the decreased angiotensin II-induced contractile responses observed in this study. It is more likely that the $\mathrm{AT}_{1}$ receptor density within the contractile tissue was decreased following the 14-week losartan treatment; however, there is a need to undertake receptor binding studies of ileal and colonic tissue after losartan treatment to determine muscarinic receptor density of: 1) ileal tissue and 2) the profile of $\mathrm{AT}_{1}$ receptors of both the ileum and colon (Leifert et al., 2009). We have previously shown that there is a depressed prostanoid response in young rats (Patten et al., 2006) and SHRs, but have not measured prostanoid receptor profiles (Patten et al., 2004, 2005). In earlier studies, we also demonstrated that dietary fish oil supplementation led to higher receptor-induced contractility in normal (Patten et al., 2002) and hypertensive rats (Patten et al., 2005) that was not explained by changes in receptor
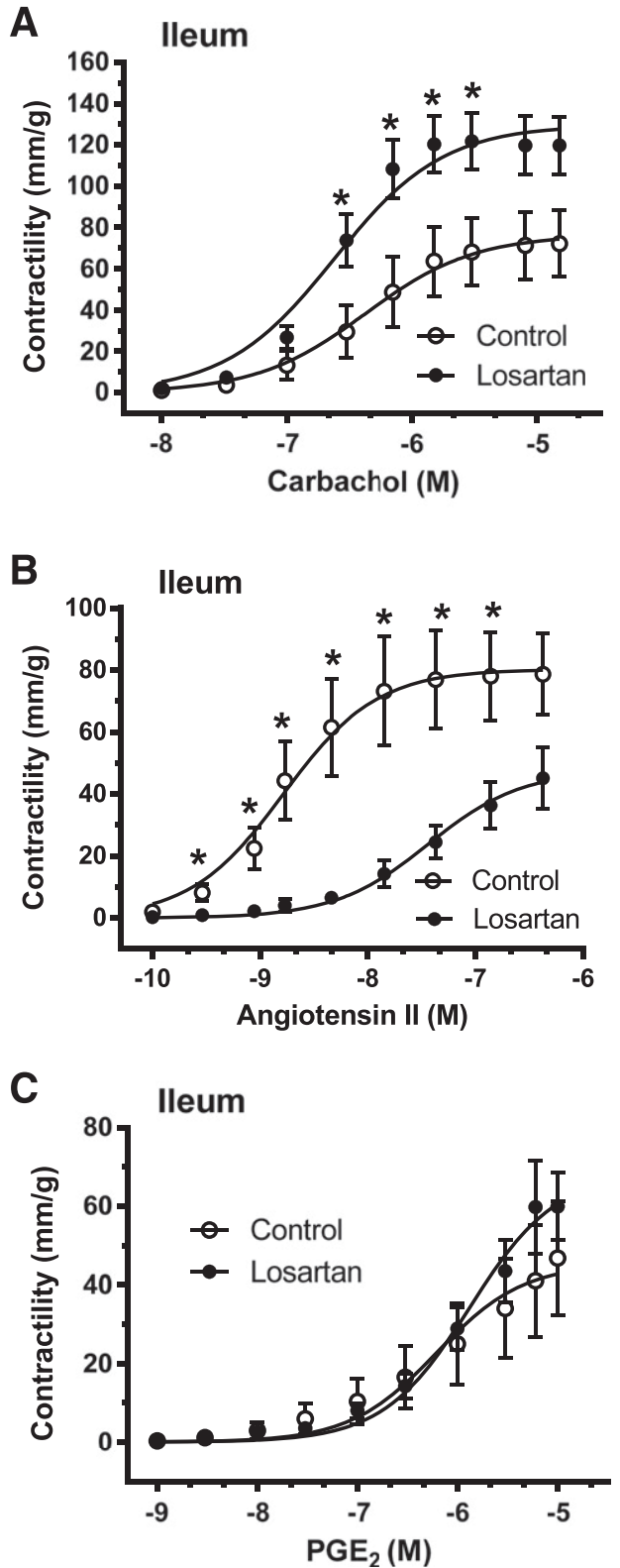

Fig. 3. Experiment 2. The dose accumulative effects of carbachol (A), angiotensin II (B), and $\mathrm{PGE}_{2}(\mathrm{C})$ on intact ileal sections ex vivo after 16-week treatment with losartan (filled circles) from 25-week-old SHRs compared with no-treatment SHR controls (open circles). The data are expressed as the mean \pm S.E.M. from six to eight rats. Using Student's $t$ tests, there were significant differences at the doses shown for carbachol and angiotensin II and between the groups $(P<0.05)$. The calculated maximal contraction $(\mathrm{mm} / \mathrm{g})$, sensitivity $\left(\mathrm{EC}_{50}\right)$, and area under the curve for the gastrointestinally active agents in the ileum are shown in Table 3.

number or sensitivity (Patten et al., 2005), although it was determined fish oil could lead to altered sensitivity of muscarinic 1 receptor subtype (Patten et al., 2006). We have recently shown that dietary resistant starch can alter colonic contractility in healthy adult rats, and demonstrated alterations in colonic expression of genes related to systems that influence gastrointestinal contractility using genomic microarray techniques (Patten et al., 2015b) that may be used to discern losartan effects shown in this study on the intestinal genome. It is also to be determined if other ARBs, such as olmesartan, which has been reported to have some evidence 


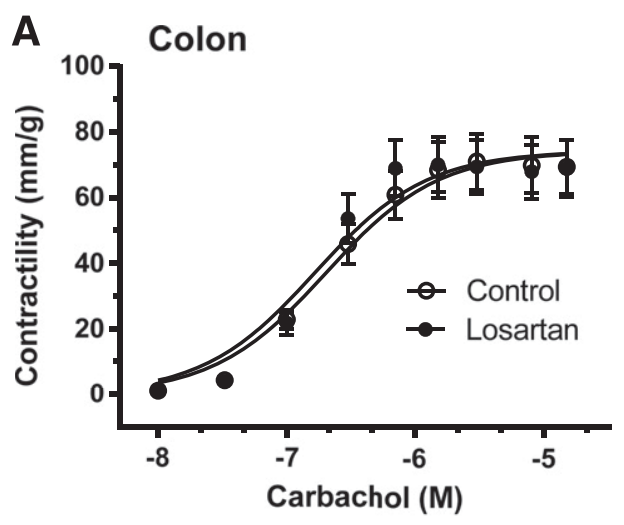

B

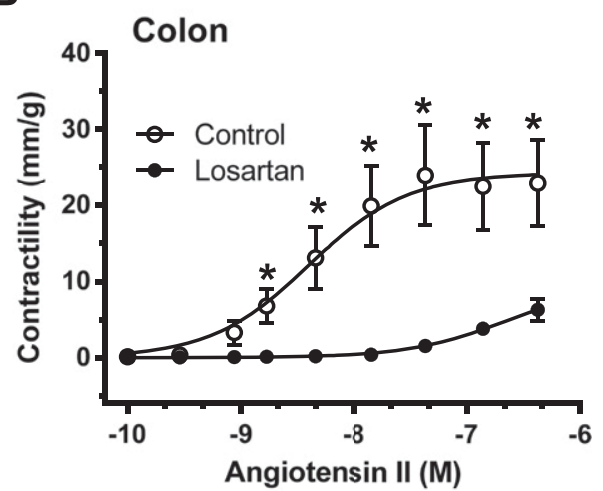

C

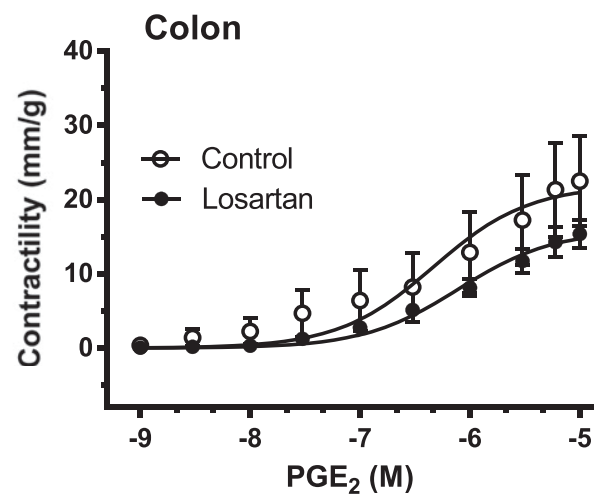

Fig. 4. Experiment 2. The dose accumulative effects of carbachol (A), angiotensin $\mathrm{II}(\mathrm{B})$, and $\mathrm{PGE}_{2}$ (C) on intact proximal colonic sections ex vivo after 16-week treatment with losartan (filled circles) from 25-week-old SHRs compared with no-treatment SHR controls (open circles). The data are expressed as the mean \pm S.E.M. from six to eight rats. Using Student's $t$ tests, there were significant differences at the doses shown for angiotensin II between the groups $(P<0.05)$. The calculated maximal contraction $(\mathrm{mm} / \mathrm{g})$, sensitivity $\left(\mathrm{EC}_{50}\right)$, and area under the curve for the gastrointestinally active agents and electrical stimulation in the colon are shown in Table 3.

associating it with gut disorders (Basson et al., 2016), also influence SHR gut contractility, especially in angiotensin receptor-driven systems (Miura et al., 2011; Singh and Karnik, 2016).

In conclusion, the current study in part supports our hypothesis that antihypertensive drug treatment affects intestinal contractility in SHRs. The ACE inhibitor enalapril and the arterial relaxant hydralazine had no effect on gut tissue contractility ex vivo. However, the ARB losartan increased receptor-independent $\mathrm{KCl}$-induced and muscarinic-induced contractility of the ileum, whereas the angiotensin-receptor system was severely depressed in both ileal and colonic tissue by mechanisms that are to be determined. This is the first description of altered smooth muscle contractility induced by losartan in a hypertensive animal model, and we may speculate that this phenomenon in part explains some adverse side effects of ARB treatment of high blood pressure.

\section{Acknowledgments}

The authors thank Julie Dallimore and Michael Adams for their technical assistance with this study.

\section{Authorship Contributions}

Participated in research design: Patten, Abeywardena.

Conducted experiments: Patten.

Performed data analysis: Patten.

Wrote or contributed to the writing of the manuscript: Patten, Abeywardena.

\section{References}

Bajka BH, Clarke JM, Topping DL, Cobiac L, Abeywardena MY, and Patten GS (2010) Butyrylated starch increases large bowel butyrate levels and lowers colonic smooth muscle contractility in rats. Nutr Res 30:427-434.

Basson M, Mezzarobba M, Weill A, Ricordeau P, Allemand H, Alla F, and Carbonnel F (2016) Severe intestinal malabsorption associated with olmesartan: a French nationwide observational cohort study. Gut 65:1664-1669. 10.1136/gutjnl-2015309690.

Bennett A, Eley KG, and Scholes GB (1968) Effects of prostaglandins E1 and E2 on human, guinea-pig and rat isolated small intestine. Br J Pharmacol 34:630-638.

Bhaskaran K, Douglas I, Evans S, van Staa T, and Smeeth L (2012) Angiotensin receptor blockers and risk of cancer: cohort study among people receiving antihypertensive drugs in UK General Practice Research Database. BMJ 344:e2697 10.1136/bmj.e2697.

Chiba T, Shibamura S, Tanaka M, Yamasaki T, Hashimoto H, Kurebayashi Y, Kasai Y, Ryokawa Y, Tamura K, Hirohashi M, et al. (1981) Antihypertensive and general pharmacological properties of budralazine. Arzneimittelforschung 31:1080-1087.

Cole-Jeffrey CT, Liu M, Katovich MJ, Raizada MK, and Shenoy V (2015) ACE2 and microbiota: emerging targets for cardiopulmonary disease therapy. $J$ Cardiovasc Pharmacol 66:540-550.

Dickstein K, Timmermans P, and Segal R (1998) Losartan: a selective angiotensin II type 1 (AT1) receptor antagonist for the treatment of heart failure. Expert Opin Investig Drugs 7:1897-1914.

Donoghue M, Hsieh F, Baronas E, Godbout K, Gosselin M, Stagliano N, Donovan M, Woolf B, Robison K, Jeyaseelan R, et al. (2000) A novel angiotensin-converting enzyme-related carboxypeptidase (ACE2) converts angiotensin I to angiotensin 1-9. Circ Res 87:E1-E9.

Duggan KA, Mendelsohn FA, and Levens NR (1989) Angiotensin receptors and angiotensin I-converting enzyme in rat intestine. Am J Physiol 257:G504-G510.

Garg M, Angus PW, Burrell LM, Herath C, Gibson PR, and Lubel JS (2012) Review article: the pathophysiological roles of the renin-angiotensin system in the gastrointestinal tract. Aliment Pharmacol Ther 35:414-428.

Geboes K, De Hertogh G, and Ectors N (2006) Drug-induced pathology in the large intestine. Curr Diagn Pathol 12:239-247.

Gokhale N, Shahani S, and Pawar D (2002) Efficacy and safety of losartanamplodipine combination-an Indian postmarketing surveillance experience. J Indian Med Assoc 100:207-208.

Graça I, Sousa EJ, Costa-Pinheiro P, Vieira FQ, Torres-Ferreira J, Martins MG, Henrique R, and Jerónimo C (2014) Anti-neoplastic properties of hydralazine in prostate cancer. Oncotarget 5:5950-5964.

Hashimoto T, Perlot T, Rehman A, Trichereau J, Ishiguro H, Paolino M, Sigl V, Hanada T, Hanada R, Lipinski S, et al. (2012) ACE2 links amino acid malnutrition to microbial ecology and intestinal inflammation. Nature 487:477-481.

Hirasawa K, Sato Y, Hosoda Y, Yamamoto T, and Hanai H (2002) Immunohistochemical localization of angiotensin II receptor and local renin-angiotensin system in human colonic mucosa. J Histochem Cytochem 50:275-282.

Iizuka Y, Kuwahara A, and Karaki S (2014) Role of PGE2 in the colonic motility: PGE2 generates and enhances spontaneous contractions of longitudinal smooth muscle in the rat colon. J Physiol Sci 64:85-96.

Klimas J, Olvedy M, Ochodnicka-Mackovicova K, Kruzliak P, Cacanyiova S, Kristek F, Krenek P, and Ochodnicky P (2015) Perinatally administered losartan augments renal ACE2 expression but not cardiac or renal Mas receptor in spontaneously hypertensive rats. J Cell Mol Med 19:1965-1974.

Knowles HJ, Tian Y-M, Mole DR, and Harris AL (2004) Novel mechanism of action for hydralazine: induction of hypoxia-inducible factor-1alpha, vascular endothelial growth factor, and angiogenesis by inhibition of prolyl hydroxylases. Circ Res 95: $162-169$.

Kuba K, Imai Y, and Penninger JM (2013) Multiple functions of angiotensinconverting enzyme 2 and its relevance in cardiovascular diseases. Circ $J$ 77: 301-308.

Lagana SM, Braunstein ED, Arguelles-Grande C, Bhagat G, Green PH, and Lebwohl B (2015) Sprue-like histology in patients with abdominal pain taking olmesartan compared with other angiotensin receptor blockers. J Clin Pathol 68:29-32. 
Lee C, Chun J, Hwang SW, Kang SJ, Im JP, and Kim JS (2014) Enalapril inhibits nuclear factor-кB signaling in intestinal epithelial cells and peritoneal macrophages and attenuates experimental colitis in mice. Life Sci 95:29-39.

Leifert WR, Bucco O, Abeywardena MY, and Patten GS (2009) Radioligand binding assays: application of [(125)I] angiotensin II receptor binding. Methods Mol Biol 552:131-141.

Mastropaolo M, Zizzo MG, Auteri M, Caldara G, Liotta R, Mulè F, and Serio R (2015) Activation of angiotensin II type 1 receptors and contractile activity in human sigmoid colon in vitro. Acta Physiol (Oxf) 215:37-45.

Mastropaolo M, Zizzo MG, Mulè F, and Serio R (2013) Angiotensin II contractile effects in mouse colon: role for pre- and post-junctional AT(1A) receptors. Acta Physiol (Oxf) 207:337-345.

Miura S, Karnik SS, and Saku K (2011) Review: angiotensin II type 1 receptor blockers: class effects versus molecular effects. J Renin Angiotensin Aldosterone Syst 12:1-7 http://www.sagepub.co.uk/journalspermission.nav.

Patten GS, Abeywardena MY, McMurchie EJ, and Jahangiri A (2002) Dietary fish oil increases acetylcholine- and eicosanoid-induced contractility of isolated rat ileum. J Nutr 132:2506-2513.

Patten GS, Abeywardena MY, Sundram K, Tan YA, and Sambanthamamurthi R (2015a) Effect of palm oil phenolics on gastrointestinal transit, contractility and motility in the rat. $J$ Funct Foods 17:928-937.

Patten GS, Adams MJ, Dallimore JA, and Abeywardena MY (2004) Depressed prostanoid-induced contractility of the gut in spontaneously hypertensive rats (SHR) is not affected by the level of dietary fat. J Nutr 134:2924-2929.

Patten GS, Adams MJ, Dallimore JA, Rogers PF, Topping DL, and Abeywardena MY (2005) Restoration of depressed prostanoid-induced ileal contraction in spontaneously hypertensive rats by dietary fish oil. Lipids 40:69-79.

Patten GS, Conlon MA, Bird AR, Adams MJ, Topping DL, and Abeywardena MY (2006) Interactive effects of dietary resistant starch and fish oil on short-chain fatty acid production and agonist-induced contractility in ileum of young rats. Dig Dis Sci 51:254-261.

Patten GS, Kerr CA, Dunne RA, Shaw JM, Bird AR, Regina A, Morell MK, Lockett TJ, Molloy PL, Abeywardena MY, et al (2015b) Resistant starch alters colonic contractility and expression of related genes in rats fed a Western diet. Dig Dis Sci 60:1624-1632.

Perlot T and Penninger JM (2013) ACE2 - from the renin-angiotensin system to gut microbiota and malnutrition. Microbes Infect 15:866-873.

Pontieri V, Lopes OU, and Ferreira SH (1990) Hypotensive effect of captopril. Role of bradykinin and prostaglandinlike substances. Hypertension 15(2, Suppl)I55-I58.

Sciolom S, Malamut G, Meresse B, Guegan N, Brousse N, Verarre V, Derrieux C, Macintyre E, Seksik P, and Savoye G, et al. (2015) Gastrointestinal disorder associated with olmesartan mimics autoimmune enteropathy. PLoS One 10: e0125024 DOI: 10.1371/journal.pone.0125024.

Sechi LA, Valentin JP, Griffin CA, and Schambelan M (1993) Autoradiographic characterization of angiotensin II receptor subtypes in rat intestine. Am J Physiol 265:G21-G27.

Sim MK and Chen WS (2006) Effects of losartan on angiotensin receptors in the hypertrophic rat heart. Regul Pept 137:140-146.

Simpson KL and McClellan KJ (2000) Losartan: a review of its use, with special focus on elderly patients. Drugs Aging 16:227-250.

Singh KD and Karnik SS (2016) Angiotensin receptors: structure, function, signaling and clinical applications. J Cell Signal 1:111 10.4172/jes.1000111.

Spak E, Casselbrant A, Olbers T, Lönroth H, and Fändriks L (2008) Angiotensin II-induced contractions in human jejunal wall musculature in vitro. Acta Physiol (Oxf) 193:181-190.

Spencer AU, Yang H, Haxhija EQ, Wildhaber BE, Greenson JK, and Teitelbaum DH (2007) Reduced severity of a mouse colitis model with angiotensin converting enzyme inhibition. Dig Dis Sci 52:1060-1070.

Tipnis SR, Hooper NM, Hyde R, Karran E, Christie G, and Turner AJ (2000) A human homolog of angiotensin-converting enzyme. Cloning and functional expression as a captopril-insensitive carboxypeptidase. J Biol Chem 275:33238-33243.

Wang L, Zhao JW, Liu B, Shi D, Zou Z, and Shi XY (2012) Antihypertensive effects of olmesartan compared with other angiotensin receptor blockers: a meta-analysis. Am J Cardiovasc Drugs 12:335-344.

Weber M (1997) Clinical safety and tolerability of losartan. Clin Ther 19:604-616, discussion 603.

Weingärtner O, Weingärtner N, Böhm M, and Laufs U (2009) Bad gut feeling: ACE inhibitor induced intestinal angioedema. BMJ Case Rep 2009:bcr09.2008.0868 10.1136/bcr.09.2008.0868.

Yang T, Santisteban MM, Rodriguez V, Li E, Ahmari N, Carvajal JM, Zadeh M, Gong M, Qi Y, Zubcevic J, et al. (2015) Gut dysbiosis is linked to hypertension. Hypertension 65:1331-1340.

Zeino Z, Sisson G, and Bjarnason I (2010) Adverse effects of drugs on small intestine and colon. Best Pract Res Clin Gastroenterol 24:133-141.

Zhu Z, Xiong S, and Liu D (2016) The gastrointestinal tract: an initial organ of metabolic hypertension? Cell Physiol Biochem 38:1681-1694.

Address correspondence to: Glen Stephen Patten, CSIRO Health and Biosecurity, Kintore Avenue, P.O. Box 10041, Adelaide BC, SA 5000, Australia. E-mail: glen.patten@csiro.au 